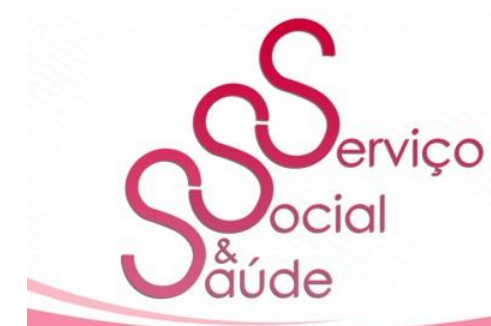

ISSN 2446-5992

(๑)

doi: 10.20396/sss.v20i00.8667831

\title{
RESEÑA
}

\section{Vivir en tiempos convulsionados}

\section{Reflexiones sociocríticas para propuestas de intervención social}

\author{
Living in turbulent times
}

Social-critical considerations for proposals on social intervention

\author{
Johanna Madrigal Calderón ${ }^{1}$
}

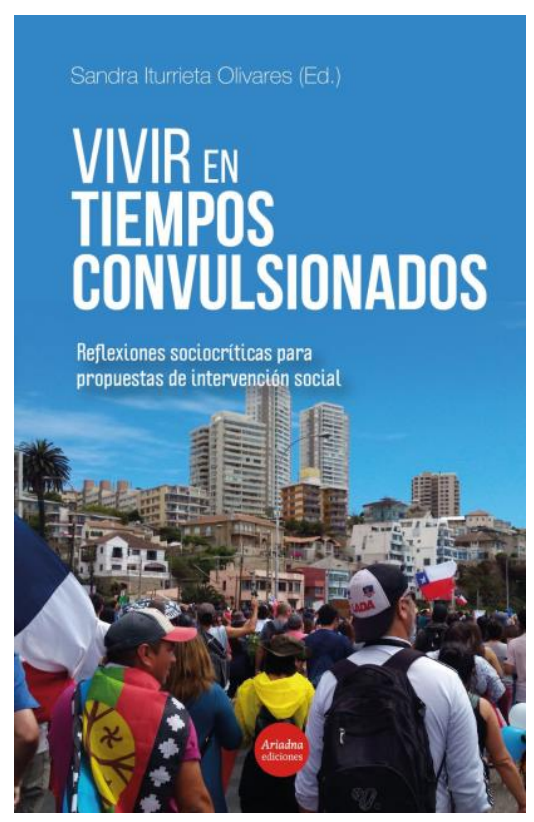

ITURRIETA, Sandra (Ed.). Vivir en tiempos convulsionados. Reflexiones sociocríticas para propuestas de intervención social. Santiago, Chile: Ariadna Ediciones, 2021. 184 p. ISBN: 978-956-6095-21-7.

\footnotetext{
${ }^{1}$ Trabajadora social, licenciada y magíster en Trabajo Social, Pontificia Universidad Católica de Chile. Master en investigación en Sociología y doctora en Sociología, Universidad de Estrasburgo, Francia. Académica Departamento de Ciencias Sociales, Universidad de Aysén, Chile. Teléfono: 5567 2332201: E-mail: johanna.madrigal@uaysen.cl
}

\begin{tabular}{|l|l|l|l|l|r|}
\hline Serv. Soc. \& Saúde & Campinas, SP & v. 20 & e021012 & 2021 & e-ISSN 2446-5992
\end{tabular}




\section{Vivir en tiempos convulsionados. Reflexiones sociocríticas para propuestas de}

intervención social emerge del trabajo del "Núcleo de investigación sobre las profesiones en las sociedades contemporáneas" de la Pontificia Universidad Católica de Valparaíso. Bajo la dirección y coordinación de la Dra. Sandra Iturrieta Olivares, el libro es publicado por Ariadna Ediciones en 2021. En él, las reflexiones presentes demuestran el interés de sus autores por desarrollar propuestas sobre y para las y los profesionales que confluyen en espacios de intervención social, siendo esta última el principal foco de la obra.

Articulado en ocho capítulos, en este libro sus catorce autoras y autores desarrollan planteamientos de, para y desde la intervención. Dicha autorreflexividad académica, pero no "academicista", se pone en diálogo con y al servicio del ejercicio profesional desde lo material y también lo subjetivo, por lo que su lectura puede interesar tanto a profesionales de las ciencias sociales de distintos niveles de intervención - desde la implementación hasta la formulación de políticas sociales - como a analistas, estudiantes o público en general interesado en esta temática.

Situando al lector en redes de pensamiento y debates contemporáneos sobre la intervención desde una mirada sociocrítica, el libro plantea un análisis del futuro del trabajo profesional en tiempos convulsionados desde observaciones polidimensionales e interdisciplinares en tiempos marcados por los procesos sociopolíticos recientes en Chile y la pandemia mundial por COVID-19. Con ello, las ideas planteadas no se limitan únicamente a dicho análisis, sino que problematizan sus objetos de estudio desde una perspectiva propositiva formulando estrategias y acciones para abordar el futuro a partir del cuestionamiento crítico del pasado.

En el primer capítulo titulado El futuro del trabajo profesional en tiempos convulsionados, su autora, Sandra Iturrieta Olivares, propone la insumisión ante la ideología póstuma imperante en la actualidad como tarea central del pensamiento sociocrítico contemporáneo. Para enfrentar la visión incierta y poco promisoria sobre el futuro del trabajo profesional, consecuencia del presentismo de la perspectiva póstuma, Iturrieta sugiere la incorporación de una inteligencia pronóstica como habilidad profesional, la cual presupone la sustitución de la idea del tiempo lineal por la de ciclos temporales junto a una noción de futuro que estaría a nuestras espaldas. El salir de la agobiante "telaraña del presente" de los tiempos convulsionados, además caracterizados por ser distópicos y retrotópico, implicaría repensar e innovar en la formación profesional 
desde esta postura ético-política permitiendo el desarrollo de la mencionada inteligencia pronóstica. En los tiempos referidos, poner esta última en ejercicio conlleva un catastrofismo que permite actuar individual o colectivamente observando las incertidumbres y riesgos como posibilidades futuras abiertas, proyectándonos al momento posterior de un hecho, poniendo en juego no sólo capacidades cognitivas sino también saberes sensibles y experienciales en su visualización desde un pensamiento "nosótrico" del tiempo que entrega posibilidades y nuevos escenarios para mirar con optimismo el futuro.

El segundo capítulo del libro, Intervención como mediación sociotécnica, desarrollado por Raúl Hozven Valenzuela, su autor revisita el objeto del Trabajo Social -si se entiende por este a la intervención social-, situándonos en sus discusiones epistemológicas y, por tanto, también conceptuales, proponiendo una mirada no solamente social, sino además que considera una dimensión sociotécnica como central en las argumentaciones en torno a esta. Hozven desarrolla los elementos de este quinto argumento en diálogo y complementando los cuatro planteados por Juan Saavedra (2015), a saber: intervención como actuación, como interpretación, como distinción sistémica y como potencial discursivo, desde una aproximación teórica del actor(actriz) red (TAR). Este sustento permite comprender lo social como un compuesto de hibrideces, controversias y reensambles entre actantes humanos/as y no humanos/as que se conectan en red.

Con ello, el autor releva la consideración de estos últimos en la intervención social desde el principio de simetría de la TAR; al igual que las personas, las maquinarias tecnológicas debiesen ser consideradas en el estudio de las sociedades en un mismo plano de inmanencia e irreductibilidad. Asimismo, en cuanto a la mediación como eje de la intervención social sociotécnica con un potencial de traducción, esta se comprende además desde su vinculación con el espacio-tiempo, donde al encontrarse eventualmente actantes en temporalidades diversas, se propone descajanegrizarles descubriendo programas de acción con posible capacidad de agencia en el presente, propiciando redes de mediación. En esto también radica una de las fortalezas de la propuesta de Hozven de una intervención como mediación sociotécnica, en cuanto a su posibilidad de conexión de agenciamientos y materialidades diversos que en conjunto constituyen prácticas profesionales.

En cuanto al capítulo titulado El derecho a voz y la conciencia del lugar de enunciación: oportunidades y propuestas desde la sistematización de las autoras Mitzi 
Duboy Luengo y Sandra Iturrieta Olivares, las reflexiones giran en torno a la pregunta por las formas de producción del conocimiento y sus apuestas políticas de la mano de propuestas para la sistematización. Comenzando con un análisis de los obstáculos epistemológicos planteados por Bachelard (2013) que conforman los modos cómo nos acercamos a nuestros objetos de estudio, las autoras exponen nudos críticos que nublan la posibilidad de aparición de otras voces distintas a las hegemónicas al momento de generar conocimiento e invitan a una reflexión crítica, responsable y respetuosamente nuestros propios lugares de enunciación. Visualizan, además, la apertura de espacios para ejercer su derecho a voz a aquellos sistemáticamente silenciados; en ese ejercicio, una de las vías para ese desarrollo es la sistematización, la cual re-conociendo y transparentando sus puntos de partida en la consecución de un objetivo en función de cómo se piensa la vida y la propia producción de conocimiento, no permite por tanto referir a una epistemología pura.

Dicho ejercicio se plantea como acto de colectivización de sentido, que reconoce las discusiones en Trabajo Social junto a las miradas de/des/pos/anti coloniales y una vigilancia epistémica ante posibilidades extractivistas del quehacer académico y vital, y más aún en la sistematización, la cual desde su dimensión política -formulada a partir de la analéctica de la filosofía de la liberación de Dussel- considera el respeto al derecho a voz de las distintas actorías sociales involucradas, reconociendo su otredad. Las autoras, destacando el legado de las intelectualidades de la sistematización como acto de memoria, en un ejercicio de recursividad, llevan a cabo lo propuesto, es decir, dar cuenta del proceder de las concepciones e influencias iniciales, para y, a su vez, devolver protagonismo al debate sobre producción de conocimientos planteado.

El cuarto capítulo del libro se titula Intervención social, alteridad y fronteras: el caso de una investigación participativa. Su autor, Clément Colin, despliega su propuesta en torno a experiencias de alteridad en talleres llevados a cabo en su investigación con habitantes adultos/as mayores de tres cerros de la ciudad de Valparaíso. En la búsqueda de desarrollar espacios de co-construcción del conocimiento con las y los participantes para transformarles en colaboradores del proyecto y de la producción de saberes, Colin identifica límites vinculados principalmente a relaciones sociales e intersubjetivas en los que están en juego representaciones e identidades sociales, poderes y construcciones de legitimidad entre quienes intervienen y las personas destinatarias. En el estudio de estos límites, y gracias a la idea de frontera desplegada en la propuesta de observación 
etnográfica de los talleres, se propone abordar la intervención social como instancia y momento en el que se revelan múltiples procesos de fronterización y desfronterización, los cuales son invisibles, sutiles, subjetivos y simbólicos y se expresan en las relaciones entre los organizadores y participantes de la intervención a través de sus palabras, discursos y también en el cuerpo y su actuación. Dicha propuesta no busca resolver estas tensiones y conflictos, sino más bien contribuir a la co-construcción de conceptos, categorías e ideas de interpretación que facilitarían su comprensión en los procesos de intervención social, por lo que la intervención misma no queda reducida a una herramienta, sino también es considerada como objeto de investigación.

Christian Arriagada Díaz y Ariel Rosales Úbeda en su capítulo Dimensiones relevantes para el análisis de la toma de decisiones en la intervención social en contextos de desastres, plantean - desde una visión crítica del concepto de desastre - importantes contribuciones para afrontar dilemas e incertidumbres del ejercicio profesional en intervención social. En base a los debates en torno a la pandemia por COVID-19 y los desafíos de la implementación de programas sociales en este panorama, Arriagada y Rosales sostienen que la sobrecarga en los servicios de atención directa tiene un efecto inmediato hacia las y los profesionales a su cargo y en sus condiciones de trabajo.

Consecuentemente, identifican la preponderancia de una visión tradicional conservadora y tecnológica - en los procesos de intervención sobre desastre desde el Trabajo Social, centrada en la entrega de una respuesta inmediata en las condiciones reactivas sobre la emergencia y el post desastre. Proponen avanzar en una reflexión disciplinar respecto de las tensiones en los procesos de intervención que vaya más allá del contexto inmediato y que cuestione la poca participación en la toma de decisiones de los profesionales de intervención de primera línea. Los autores subrayan la atención a la discrecionalidad y a la categorización de dichos profesionales, ya que en la implementación podrían expresarse ciertos juicios morales sobre los públicos o existir diferencias entre los objetivos organizacionales y los individuales de estos profesionales. A partir de ello, proponen observar estas posibles tensiones en cuatro dimensiones analíticas para la toma de decisiones en intervención, las que operan de manera superpuesta y permiten considerar efectos y consecuencias para los diferentes participantes profesionales, personas usuarias y la propia organización-, a saber: experiencial, expectativas, normativa y conceptual.

El sexto capítulo que compone el libro, escrito por Gianinna Muñoz Arce, Taly 
Reininger, Cristóbal Villalobos y Carla Morales, se titula Análisis de las condiciones laborales de trabajadoras/es sociales que implementan programas en Chile en tiempos de COVID-19. A partir de un estudio mixto secuencial sobre cambios en las condiciones de trabajo de trabajadoras/es sociales que implementan programas sociales durante la pandemia del Covid-19, sus investigadores observan una continuidad de la precarización laboral que ya afectaba a estos profesionales antes de la pandemia; con ello, identifican que el grupo que mayormente ha visto afectadas sus condiciones laborales son las/los profesionales más jóvenes, con menor formación académica y que se desempeñan en ejecución de programas. Junto a esto, articulando antecedentes sobre condiciones materiales y subjetivas, los autores proyectan desafíos y luchas para responder a la precarización, expresada principalmente en condiciones de operación que complejizan la implementación, inestabilidad laboral, bajas remuneraciones y alta carga laboral, altos niveles de estrés y burnout. Refieren también al uso e impacto de las tecnologías como posibles nuevas formas de vigilancia y control en la intervención. Además de los datos, el capítulo presenta un análisis e interpretación en el marco del neoliberalismo, del capitalismo de vigilancia y la precariedad (desde una acepción colectiva y estructural) en el sentido material y subjetivo de aquellas condiciones, a partir de los cuales se piensan espacios de resistencia profesional.

Discutiendo también en clave crítica las condiciones con las que intervienen profesionales del Trabajo Social en la primera línea en el ámbito de niñez y adolescencia, Carlos Andrade Guzmán presenta el séptimo capítulo del libro titulado Colaboración en trabajo social e intervenciones en niñez en Chile: tensiones y propuestas en materia de intradisciplina en el trabajo con niños, niñas y adolescentes. Una de las grandes contribuciones del capítulo refiere a la generación de conocimiento sobre la intradisciplina en Trabajo Social, ya que, en contraposición a las discusiones respecto a la interdisciplina, la colaboración entre personas formadas en esta misma disciplina ha sido menos atendida. En el marco de la intervención en niñez, se destaca la existencia de una gran diversidad y fragmentación en la formación de quienes componen los equipos; ello tiene su correlato en las formas en que se atiende al llamado a la colaboración para dinamizar los procesos de intervención, las cuales - desarrolladas en los marcos del neoliberalismo imperante - se llevan a cabo desde el nivel estructural (institucional y organizacional) e igualmente en las interacciones personales.

Por tanto, la variedad de maneras de significar estos espacios intradisciplinares - a 
veces contrapuestas - incide en la colaboración y, por ende, en el tipo de intervención a desarrollar. En función de lo ello, desde un análisis de narrativas de interventoras/es, el autor recalca la importancia de observar los elementos que permean y median los procesos intradisciplinares entre personas que se desempeñan en esa área, identificando los siguientes: el rol de la arquitectura normativa, los sistemas de creencias o cosmovisiones, los significados y actitudes en torno a la colaboración, las emociones involucradas, las relaciones de poder y, por último, las condiciones y recursos para la intervención con otras/os. A partir de estas discusiones y desde la teoría de roles y el institucionalismo crítico, Andrade propone un modelo para el encuentro entre interventoras/es del Trabajo Social en el campo de la niñez en los que se posibilite la colaboración. Además, el autor sugiere, para que la intervención no esté supeditada en particular a las características personales de las/los interventores, una revisión urgente de las condiciones estructurales con las que estos/as cuentan.

También en el ámbito de la niñez, el libro culmina con el capítulo que lleva por nombre Trabajo Social y saber profesional especializado en la vulneración de niñas, niños y adolescentes: análisis del PEE Casa de Acogida sur de ONG Raíces. Sus autoras María Belén Ortega Senet, Daniela Concha Araneda y Masiel Rivera Berrios, reflexionan sobre la producción de saberes y conocimiento a partir de experiencias de intervención contra la explotación sexual comercial de niños, niñas y adolescentes (ESCNNA). Por medio de un estudio cualitativo con las profesionales del programa especializado (PEE) Casa de Acogida Sur de Santiago -y mediante el análisis sobre las triadas de trabajo, el aprendizaje de las estrategias de equipo y desde el enfoque de adaptación de estas estrategias a las particularidades- se destaca la visión subjetiva de los protagonistas como fuente fundamental en la producción reflexiva de conocimiento en y para estrategias de trabajo sobre ESCNNA.

Entre sus principales hallazgos, las autoras revelan estrategias alternativas de intervención a las fragmentaciones disciplinares de las triadas psicosociales. Asimismo, destacan las formas particulares del equipo para atender las especificidades que asumen la victimización por ESCNNA, comprender y realizar su trabajo, proponiendo vínculos con elementos estructurales y de clase, desde una resignificación crítica. Las autoras finalizan presentando elementos para la discusión ética y reflexiva sobre implicancias de los saberes expuestos para el Trabajo Social y en las intervenciones en la protección de niños y niñas.

La virtuosa conjunción de estos ocho capítulos del libro Vivir en tiempos 
convulsionados. Reflexiones sociocríticas para propuestas de intervención social, se configura como una invitación a observar el quehacer en intervención social desde las experiencias de todos quienes confluyen en esos espacios y como un conjunto de modelos y propuestas ético-políticas que les permitan abordar los desafíos, el contexto y los debates actuales, en Chile y en general sociedades en América Latina, presentes en estos tiempos convulsionados, sin por ello reducirse a los límites de a una disciplina en particular sino más bien en la idea de reflexión socio-crítica intra e interdisciplinar.

Recebido em novembro de 2021 - Aprovado em novembro de 2021.

\section{REFERÊNCIA}

ITURRIETA, Sandra (Ed.). Vivir en tiempos convulsionados. Reflexiones sociocríticas para propuestas de intervención social. Santiago, Chile: Ariadna Ediciones, 2021. 184 p. Disponible en: https://ariadnaediciones.cl/images/pdf/VivirEnTiemposConvulsionados.pdf 